\title{
Sonographic Signs of Perinatal Infection
}

\author{
${ }^{1}$ Stavros Natsis, ${ }^{2}$ Panos Antsaklis, ${ }^{3}$ Themos Grigoriadis, ${ }^{4}$ Aris Antsaklis
}

\begin{abstract}
Evaluation of the patient at risk for fetal infection is challenging. Serologic studies may be inconclusive and often do not provide meaningful information about prognosis. Recent technologic advances have expanded the role of prenatal ultrasound in both anomaly detection and guidance for invasive diagnostic procedures. For the patient with a known or suspected fetal infection, sonographic identification of characteristic abnormalities can provide useful information for counseling and perinatal management.

This article reviews the sonographic manifestations of fetal infection and the role of ultrasound in the evaluation of the fetus at risk for congenital toxoplasmosis, rubella, cytomegalovirus (CMV), and the herpes viruses (TORCH infections).
\end{abstract}

Keywords: Infection, Perinatal, TORCH, Ultrasound.

How to cite this article: Natsis $S$, Antsaklis $P$, Grigoriadis T, Antsaklis A. Sonographic Signs of Perinatal Infection. Donald School J Ultrasound Obstet Gynecol 2015;9(3):275-279.

Source of support: Nil

Conflict of interest: None

\section{INTRODUCTION}

In utero infection of the fetus has become recognized as an important cause of fetal and neonatal morbidity and mortality. As our awareness of the number of pathogenic organisms increases, so too does our appreciation to the potential for in utero diagnosis of these infections. The toxoplasmosis, rubella, cytomegalovirus herpes simplex (TORCH) complex is describing a group of clinically similar congenital infections caused by toxoplasma gondii, rubella virus, cytomegalovirus, herpes simplex virus, and other, such as syphilis, varicella zoster virus, hepatitis B and human immunodeficiency virus (HIV). Soon it became clear that the collective term 'TORCH' is considered too limited to denote the entire spectrum of congenital infections and the host of organisms that have been included as perpetrators of perinatal infections, include enteroviruses, listeria, parvovirus B 19, Plasmodium and Mücobacterium tuberculosis and several others.

\footnotetext{
1-41st Department of Obstetrics and Gynecology, Department of Fetal Maternal Medicine, Alexandra Maternity Hospital University of Athens, Greece
}

Corresponding Author: Panos Antsaklis, 1st Department of Obstetrics and Gynecology, Department of Fetal Maternal Medicine Alexandra Maternity Hospital, University of Athens, Greece Phone: +32107771386, e-mail: panosant@gmail.com
Both anatomic and functional abnormalities in the fetus have been described for many types of infection. Ultrasound can play a crucial role in the diagnosis of a congenital infection and the parental counseling and infant management. Intrauterine infection can present with a wide spectrum of ultrasound markers and lesions depending on the type of the organism and the age of pregnancy when the infection occurred and the most important the time interval between the infection and the ultrasound examination. There are two cases were ultrasound can help with the prenatal diagnosis. The first case, which is more difficult, is when the clinician is encountered with some abnormal findings during a routine fetal ultrasound which are indicative of fetal infection. The second situation is when the diagnosis is confirmed with serology screening methods and the mother is referred for ultrasound to assess the severity of the infection to the fetus. ${ }^{1}$

Ultrasound will disclose any structural and growth abnormalities indicative of fetal infection, such as intrauterine growth retardation (IUGR), ventriculomegaly, oligohydramnios, hyperechogenic bowel, polyhydramnios, hydrops, brain calcifications, pleural effusion and placental enlargement (Table 1). Ultrasonographic findings are not diagnostic because they share common features with other fetal diseases. In addition, ultrasound abnormalities are observed in only less than half of the infected fetuses. ${ }^{2}$

\section{PATHOPHYSIOLOGY}

The placenta plays an integral role in all congenital viral infections, because viruses must cross and infect the placenta in order to reach the fetus. Many potential routes and mechanisms of infection of the fetus have been proposed. Intrauterine infections usually enter the fetus by either ascending or hematogenous routes. Latent endometrial infections may be another source in some instances and may cause early spontaneous abortions. The placenta consists a protective barrier for transplacental transmission of viral particles in most cases. Cells that become infected during maternal viremia are syncytial or intermediate trophoblastic cells and intravillous microphages. These cells may act as a potential source for fetal infection. If the infection is established in the placenta, an inflammatory response may be seen in the chorionic villi, producing morphological alterations concordant with villitis. ${ }^{3}$ The infection first affects the placenta and it is spreading through the umbilical cord 
to the fetus where it can cause lesions to the liver, heart, kidneys and the brain of the fetus. Some investigators have concluded that the lesions caused by the infection have to do with the gestational age in which the infection occurred. ${ }^{4}$

\section{ABNORMALITIES OF PLACENTAL SIZE}

Both abnormally large ('placentomegaly') and abnormally small placentae have been associated with intrauterine infection. Placental thickening or enlargement has been reported most frequently. Placental size usually is assessed subjectively, although a normogram for placental thickness has been published. ${ }^{5}$ A false-positive diagnosis of placental thickening can be made when the surface area of myometrial attachment is unusually small; the clinician should be aware of this potential pitfall.

\section{ABNORMALITIES OF AMNIOTIC FLUID VOLUME}

Hydramnios (increased amniotic fluid volume) and oligohydramnios (decreased volume) have been reported with similar frequency in cases of intrauterine infection. ${ }^{6}$ Various criteria for the diagnosis of abnormal amniotic fluid volume have been proposed, including subjective assessment, measurement of the single largest vertical fluid pocket, and the amniotic fluid index (AFI). The AFI, as described by Phelan et al is the sum of the measurements of the largest vertical fluid pocket in each of the four quadrants of the uterus. Moore and Cayle ${ }^{7}$ published reference values for the AFI from 16 to 42 weeks of gestation, which has become the standard for objective assessment of amniotic fluid volume.

\section{HEPATOMEGALY AND SPLENOMEGALY}

As with the fetal heart, abnormalities of fetal liver and spleen size often are identified by subjective assessment. Nomograms are available for various measurements of both organs. The liver is most easily measured longitudinally, from the dome of the right hemidiaphragm to the tip of the right lobe. ${ }^{8}$ There is disagreement as to the optimum parameter for assessment of fetal splenic size., ${ }^{9,10}$ Hepatosplenomegaly has been reported with all of the fetal TORCH infections, but often as a transient finding.

\section{INTRA-ABDOMINAL CALCIFICATIONS AND HYPERECHOIC BOWEL}

Fetal intra-abdominal calcifications may be found in various locations, including the peritoneal surface, intestinal lumen, biliary tree, vascular structures, and organ parenchyma. ${ }^{11}$ Calcified neoplasms also have been reported. The typical sonographic appearance is that of highly echogenic foci with posterior acoustic shadowing.
Although shadowing cannot be demonstrated in every case, the absence of this finding should raise the possibility that the area in question does not represent a calcification. It sometimes can be difficult to determine the precise location of intra-abdominal calcifications, but the distinction carries important diagnostic implications. Parenchymal calcifications, seen most commonly in the liver, are associated with intrauterine infection, whereas calcifications limited to the peritoneal surface are characteristic of meconium peritonitis, and intraluminal bowel calcifications suggest obstruction. Calcifications also have been demonstrated in the fetal spleen and adrenal gland. The classic sonographic appearance of an infected fetus is that of multiple calcific foci scattered throughout the liver, often in association with hepatomegaly. Small solitary liver calcifications generally are considered benign, but should at least prompt a repeat examination and assessment of risk factors for fetal infection, as discussed earlier in this report. Hyperechoic or echogenic fetal bowel appears as an irregularly shaped mass in the lower fetal abdomen with an echogenicity similar to that of bone. It must be distinguished from echogenic colonic meconium, which is a normal third trimester finding. The significance of hyperechoic bowel, particularly in the second trimester, has been debated. It has been reported in association with fetal chromosomal abnormalities, cystic fibrosis, and growth restriction, but also as a normal variant. Recent data suggest an association between this finding and congenital infection, specifically cytomegalovirus (CMV) and toxoplasmosis. ${ }^{12}$

\section{CARDIAC ABNORMALITIES}

Cardiomegaly is the most frequently encountered cardiac manifestation of congenital infection, particularly CMV. Heart size is most easily assessed subjectively from the apical four chamber view. The fetal heart normally occupies approximately one-third of the fetal thorax at this level. The cardiothoracic ratio can be determined by dividing the circumference of the heart by the chest circumference, with both measurements obtained from the same image of the four chamber view. This ratio remains fairly constant throughout pregnancy, increasing only slightly from 0.45 at 17 weeks to 0.50 at term, with the 95th percentile approximately 0.52 in the second trimester and 0.57 in the third trimester. ${ }^{13}$ Although an objective parameter, it does not discriminate between abnormalities of heart size and those of chest circumference. Ventricular dimensions as well as free wall and septal thickness also can be measured and compared to published nomograms. ${ }^{14}$ In our experience, however, cardiomegaly associated with intrauterine infection is usually obvious from the four-chamber view, 
and detailed measurements are not required. Structural cardiac anomalies, including ventricular and atrial septal defects, pulmonic stenosis, and coarctation of the aorta, are common findings of congenital rubella infection acquired during the first 2 months of pregnancy. ${ }^{15}$ Although some of these defects may be suspected from the standard screening four-chamber and outflow tract views of the fetal heart, a more extensive evaluation often is required to confirm the diagnosis. Patients at risk for congenital rubella infection acquired during the first trimester should be referred for fetal echocardiography.

\section{HYDROPS FETALIS}

The most widely accepted definition of hydrops fetalis is the presence of serous effusions in more than one fetal body cavity or one serous effusion in conjunction with anasarca. ${ }^{16}$ The peritoneal, pleural, and pericardial spaces are most often affected. Hydramnios and placental edema commonly are associated with hydrops but are not used to make the diagnosis. Hydrops is divided into two types: immune, caused by isoimmunization, and nonimmune, which has multiple etiologies. Because the two types are indistinguishable sonographically, immune hydrops should always be excluded with maternal antibody screening before considering non-immune causes, which include cardiac and other fetal structural abnormalities, chromosomal abnormalities, alpha thalassemia, and fetal metabolic disorders, in addition to intrauterine infection. As with hepatosplenomegaly, hydrops has been reported with most of the fetal TORCH infections, but may be a transient finding.

\section{FETAL GROWTH RESTRICTION}

Intrauterine growth restriction is defined as a birth weight below an arbitrarily defined lower limit, most commonly the 10th percentile for gestational age and sex. It is classically divided into two subgroups based on morphologic characteristics. Symmetric or early onset IUGR results in a fetus that is proportionately small, whereas asymmetric IUGR is manifested by relative head sparing at the expense of abdominal and soft -tissue growth. Both subgroups of IUGR can be seen with fetal infection. Detection of IUGR is dependent on accurate determination of gestational age, which is difficult in the absence of known menstrual dates or an early examination. Serial assessment of fetal growth parameters is of considerable value in establishing the diagnosis and is recommended in all but the most extreme, obvious cases. Incorporation of ancillary information, such as amniotic fluid volume, Doppler velocimetry of fetal and umbilical vessels, and maternal history may enhance diagnostic accuracy. Intrauterine growth restriction is a common feature of congenital CMV, rubella, herpes simplex virus and varicella. It is usually not seen with congenital toxoplasmosis and syphilis, although a few cases of each have been reported.

\section{VENTRICULOMEGALY}

Two objective criteria for the diagnosis of fetal cerebral ventriculomegaly have been proposed: the lateral ventricular to hemispheric ratio (LVR) and direct measurement of the lateral ventricle. ${ }^{17}$ The LVR is calculated by dividing the lateral ventricular width (measured from the middle of the midline echo to the lateral ventricular wall in the parietal region) by the hemispheric width (measured on the same image from the middle of the midline echo to the inner table of the calvarium). This ratio remains constant from 24 weeks to term, with an upper limit of $50 \%$, but is normally much higher during early pregnancy and varies widely from 15 to 24 weeks, which limits its usefulness in the second trimester. There is also evidence that the measurement technique itself may be flawed in that it is based on the identification of an echogenic line that does not actually represent the lateral ventricular wall. ${ }^{18}$ Direct observation of the lateral ventricle is a more useful criterion, particularly in the second trimester. In an axial scanning plane rostral (superior) to the biparietal diameter level, the atrium of the lateral ventricle is easily identified using the echogenic choroid plexus as a landmark. The choroid plexus normally fills, or almost fills, the transverse dimension of the ventricle at this level. The ventricular diameter is measured at the posterior aspect of the choroid plexus. This measurement remains nearly constant at 4 to $8 \mathrm{~mm}$ from 15 weeks to term. An upper limit of $10 \mathrm{~mm}$ is most commonly used. Increased angle of the dependent choroid plexus ('dangling' choroid plexus sign) is a helpful visual clue. ${ }^{19}$ Neural tube defects are the most common cause of fetal ventriculomegaly. Approximately $5 \%$ of cases can be attributed to fetal infection. ${ }^{20}$ Ventriculomegaly is almost always symmetric; we have observed an unusual case of mild unilateral ventriculomegaly associated with $\mathrm{CMV}$ infection in our center.

\section{INTRACRANIAL CALCIFICATIONS}

This finding is considered by many to be pathognomonic of intrauterine infection, although it also can be related to noninfectious etiologies.

Periventricular hyperechoic foci are the hallmark of fetal intracranial calcifications. They are typically small and highly reflective and often do not exhibit the acoustic shadowing characteristic of intra-abdominal calcifications. ${ }^{21}$ They can be extremely subtle, particularly in the second trimester, and also may be located in the 
regions of the thalami and basal ganglia. Intracranial calcifications are most frequently seen with fetal CMV and toxoplasmosis and have been reported with congenital varicella and herpes simplex virus and rubella.

\section{HYDRANENCEPHALY}

Hydranencephaly results from intrauterine disruption of the brain and is considered the most severe manifestation of the destructive process. The cerebral hemispheres are almost entirely replaced by fluid, but the brainstem and rhombencephalic structures usually are preserved. This anomaly is easily recognized sonographically by the characteristic fluid-filled intracranial cavity with no discernible cerebral cortex. The brainstem can be seen bulging into the intracranial cavity, and the posterior fossa structures usually can be identified as well. The falx is usually present, but in some cases is deviated or absent. ${ }^{17}$ Hydranencephaly has been reported in several cases of congenital herpes simplex virus infection and as an unusual manifestation of toxoplasmosis and CMV.

\section{MICROCEPHALY}

Microcephaly, or small head size, implies a reduction of brain mass. It often is associated with other anomalies, such as encephalocele and various cerebral malformations. Sonographic findings include small biparietal diameter and head circumference, abnormal head circumference to abdominal circumference and head circumference to femur length ratios, and poor fetal head growth on serial examinations. ${ }^{17}$ There is disagreement about which anthropomorphic definition of microcephaly should be used prenatally. Chervenak et $\mathrm{al}^{22}$ proposed a head circumference threshold of three standard deviations below the mean for gestational age; this is the criterion we have adopted in our center. Because the head circumference is a gestational age-dependent parameter, incorrect dating will affect its interpretation. Head to trunk and extremity ratios may be used in conjunction with head circumference to improve specificity. The biparietal diameter should not be used independently to diagnose microcephaly because of significant variation of this measurement with head shape. Isolated microcephaly has been documented in cases of congenital CMV, herpes simplex virus, and rubella virus. It is seen less commonly with toxoplasmosis infections.

\section{PORENCEPHALY}

Porencephaly is defined as an area of focal encephalomalacia that communicates with the ventricular system, giving the appearance of a dilated ventricle. ${ }^{23}$ Porencephalic cysts can be further classified as true porencephalic cysts or pseudoporencephalic cysts. True cysts can arise either
Table 1: Abnormal ultrasound findings in

CMV-infected fetuses

\begin{tabular}{ll}
\hline Subject number & Ultrasound findings \\
\hline Periconception & Bilateral ventriculomegaly, IUGR, \\
1 & liver and brain calcifications \\
2 & Echogenic bowel \\
First trimester & \\
3 & IUGR \\
4 & IUGR \\
5 & Echogenic bowel \\
6 & Echogenic bowel \\
7 & Ascites, echogenic bowel \\
8 & Brain calcifications, echogenic bowel \\
9 & Periventricular brain cysts, \\
10 & echogenic bowel \\
11 & Dilated bowel loop \\
Second trimester & Echogenic bowel \\
12 & \\
13 & Unilateral ventriculomegaly \\
14 & Hydrops \\
15 & Microcephaly \\
& IUGR, echogenic bowel \\
\hline & Echogenic, bowel \\
16 & Small head circumference, mild \\
&
\end{tabular}

CMV: Cytomegalovirus; IUGR: Intrauterine growth restriction (Feldman. Prenatal diagnosis of primary maternal CMV. Am J Obstet Gynecol 2011).

by a defect in the generative process or by abnormal migration of the neurons. Most commonly, they are located in the region of the sylvian fissure. They may communicate with the ventricles, the cerebral cortical surface and the subarachnoid space. Porencephalic pseudocysts arise by disruption of normal brain tissue, either due to a vascular event or due to an infection. They can be unilateral and can enlarge without communicating with other structures. The cause of porencephaly associated with CMV infection is not well understood. Possible etiologies include intracerebral thrombosis, intracranial hemorrhage and a primary destructive effect of the virus itself. ${ }^{24,25}$

\section{CONCLUSION}

Ultrasound monitoring is crucial for pregnant women with proven perinatal infection because it is the only means of disclosing fetal abnormalities caused by congenital infection. Although ultrasound is not the best means to establish fetal congenital infection, it is a useful adjunct in predict the likelihood of postnatal disease caused by a congenital infection. Parental counseling can be tailored in the status of fetal infection after invasive prenatal diagnosis, supporting findings that ultrasonographic abnormalities associated with in utero fetal infection might increase the risk of adverse 
neonatal outcomes. The clinician should understand the limitations of ultrasound, discuss them with the patient, and document the discussion in the medical record. Patients should be counseled that ultrasound is not a sensitive test for fetal infection and that a normal fetal anatomy survey cannot predict a favorable outcome. In the low-risk patient, fetal infection should be considered when multiple organ system anomalies, fetal growth restriction, placental enlargement, or abnormalities of amniotic fluid volume are demonstrated.

\section{REFERENCES}

1. Lipitz S, Achiron R, Zalel Y, Mendelson E, Teperberg M, Gamzu R. Outcome of pregnancies with vertical transmission of primary cytomegalovirus infection. Obstet Gynecol 2002; 100(3):428-433.

2. La Torre R, Nigro G, Mazzocco M, Best AM, Adler SP. Placental enlargement in women with primary cytomegalovirus infection is associated with fetal and neonatal disease. Clin Infect Dis 2006;43(8):994-1000.

3. Horn LC1, Röse I. Placental and fetal pathology in intrauterine viral infections. Intervirol 1998;41(4-5):219-225.

4. Feldman B, Yinon Y, Tepperberg Oikawa M, Yoeli R, SchiffE, Lipitz S. Pregestational, periconceptional and gestational primary maternal cytomegalovirus infection: prenatal diagnosis in 508 pregnancies. Am J Obstet Gynecol 2011; 205(4):342.e1-e6.

5. Hoddick WK, Mahony BS, Callen PW, Filly RA. Placental thickness. J Ultrasound Med 1985;4(9):479-482.

6. Drose JA, Dennis MA, Thickman D. Infection in utero: US findings in 19 cases. Radiol 1991;178(2):369-374.

7. Moore TR, Cayle JE. The amniotic fluid index in normal human pregnancy. Am J Obstet Gynecol 1990;162(5):1168-1173.

8. Vintzileos AM, Neckles S, Campbell WA, Andreoli JW Jr, Kaplan BM, Nochimson DJ. Fetal liver ultrasound measurements during normal pregnancy. Obstet Gynecol 1985; 66(4):477-480.

9. Aoki S, Hata T, Kitao M. Ultrasonographic assessment of fetal and neonatal spleen. Am J Perinatol 1992;9(5-6):361-357.

10. Schmidt W, Yarkoni S, Jeanty P, Grannum P, Hobbins JC. Sonographic measurements of the fetal spleen: clinical implications. J Ultrasound Med 1985;4(12):667-672.

11. Nyberg DA. Intra-abdominal abnormalities. In: Nyberg DA, Mahony, Barry S Pretorius, Dolores H., editors. Diagnostic
Ultrasound of Fetal Anomalies: Text and Atlas. Chicago, IL: Year Book Medical Publishers; 1990. p. 83-145.

12. MacGregor SN, Tamura R, Sabbagha R, Brenhofer JK, Kambich MP, Pergament E. Isolated hyperechoic fetal bowel: significance and implications for management. Am J Obstet Gynecol 1995;173(4):1254-1258.

13. Paladini D, Chita SK, Allan LD. Prenatal measurement of cardiothoracic ratio in evaluation of heart disease. Arch Dis Child 1990;65(1):20-23.

14. Drose JA. Scanning: Indications and technique. In: Drose JA, editor. Fetal Echocardiography. Philadelphia, PA: W.B. Saunders; 1998. p.15-57.

15. Cooper, LZ.; Preblud, SR.; Alford, CA Jr. Rubella. In: Remington, Jack S.; Klein, JO., editors. Infectious diseases of the fetus and new-born infant. 4th ed. Philadelphia, PA: W.B. Saunders; 1995. p. 268-311.

16. Mahony BS, Filly RA, Callen PW, Chinn DH, Golbus MS. Severe nonimmune hydrops fetalis: sonographic evaluation. Radiol 1984;151(3):757-761.

17. Nyberg, David A.; Pretorius DH. Cerebral malformations. In: Nyberg, DA.; Mahony, BS.; Pretorius, DH., editors. Diagnostic Ultrasound of Fetal Anomalies: Text and Atlas. Chicago, IL: Year Book Medical Publishers; 1990.

18. Bowerman RA, DiPietro MA. Erroneous sonographic identification of fetal lateral ventricles: relationship to the echogenic periventricular 'blush'. Am J Neuroradiol 1987; 8(4):661-664.

19. Cardoza JD, Filly RA, Podrasky AE. The dangling choroid plexus: a sonographic observation of value in excluding ventriculomegaly. Am J Roentgenol 1988;151(4):767-770.

20. Holzgreve W, Feil R, Louwen F, Miny P. Prenatal diagnosis and management of fetal hydrocephaly and lissencephaly. Child's Nerv Syst 1993;9(7):408-412.

21. Fakhry J, Khoury A. Fetal intracranial calcifications: The importance of periventricular hyperechoic foci without shadowing. J Ultrasound Med 1991;10(1):51-54.

22. Chervenak FA, Jeanty P, Cantraine F, Chitkara U, Venus I, Berkowitz RL, Hobbins JC. The diagnosis of fetal microcephaly. Am J Obstet Gynecol 1984;149(5):512-517.

23. Grossman, Robert I, Yousem, David M. Neuroradiology: the requisites. St Louis; Mosby; 1994. p. 225-246.

24. Moinuddin A, McKinstry RC, Martin KA, Neil JJ. Intracranial hemorrhage progressing to porencephaly as a result of congenitally acquired cytomegalovirus infection an illustrative report. Prenat Diagn 2003;23(10):797-800.

25. Crino J. Ultrasound and Fetal Diagnosis of Perinatal Infection. Clinical Obstet Gynecol 1999;42(1):71-80. 